\title{
Macro Seminogramn Neat Semen of a Kangayam Bull - An Ingenious Study
}

\author{
Elamurugan Krishnamoorthy ${ }^{1}$, Ezakial Napoleon², Selvaraju Mani ${ }^{3 *}$, \\ Murali Nagarajan ${ }^{4}$ and Palanisamy Mahakrishnan ${ }^{1}$
}

\begin{abstract}
${ }^{1}$ Department of Veterinary Gynaecology and Obstetrics, ${ }^{2}$ Department of Clinics, Veterinary Clinical Complex, ${ }^{3}$ Veterinary University Training and Research Centre, ${ }^{4}$ Department of Animal Genetics and Breeding, Veterinary College and Research Institute, Namakkal, Tamilnadu Veterinary and Animal Sciences University, Tamil Nadu, India
\end{abstract}

*Corresponding author

Keywords

Kangayam Bull, Neat semen, Macro seminogram, Seminal attributes

Article Info

Accepted:

15 September 2020 Available Online: 10 October 2020

\section{A B S T R A C T}

\section{Introduction}

The Kangayam breed of cows is a dual purpose breed with maximum milk yield of 1,455 litres and it is distributed in Erode, Dindigul, Karur, Coimbatore, Salem and Namakkal districts of Tamil Nadu. It is best known for its superior draught qualities, adaptation to poor nutrition and longevity, a pair of bullocks has the capacity to haul a total load of $3787 \pm 51.4 \mathrm{~kg}$ of sugarcane load over a distance of 10 to $20 \mathrm{~km}$ without taking rest (Kandasamy, 2001). As per the estimate of 1996, the size of Kangayam population in the breeding tract was 0.479 million and it got reduced to 80,620 in 2013. Artificial insemination (AI) has become an inevitable tool in the breeding management of most of the domestic animals.

This technology helps to propagate the male germplasm in a faster way. It has been successfully implemented in breeding of bovines but is still lacking in indigenous cattle 
breeds. Semen cryopreservation prolongs the life of spermatozoa by decreasing metabolism and toxin production (Curry, 2000 and Bailey et al., 2003).

Kangayam cattle are in the verge of declining populations. However, recent awareness on rearing native cattle has prompted the importance of this breed. There is still long gap between the breeds and scientists to come out with good quality Frozen Semen Straws (FSS) from pedigreed Kangayam bulls.

Limited availability of Kangayam bulls in the present scenario demands the adoption of techniques like semen collection, semen preservation and artificial insemination for the conservation and perpetuation of this unique germplasm.

Seminal attributes in neat semen were analyzed in Hariana bulls (Ajendar Singh Pal et al., 2020); Hallikar bulls (Prem Kumar et al., 2020); Sahiwal bulls (Ahmad et al., 2003); Tharparkar bulls (Bhosrekar et al., 1972); Punganur bulls (Bramhaiah et al., 2013); Gir bulls (Chikhaliya et al., 2018); Kankrej bulls (Patel et al., 2013); Red Sindhi bulls (Ritesh Tiwari et al., 2012); Ongole bulls (Rao et al., 2000) and Boer crossbred bucks (Manivannan et al., 2017). This study is the first attempt in analyzing the macroscopic seminal attributes in a Kangayam bull.

\section{Materials and Methods}

\section{Source of experimental animal}

Kangayam Bull No. NK14 named Nagulan, aged 5 years which is maintained at Frozen Semen Bank, Department of Veterinary Gynaecology and Obstetrics, Veterinary College and Research Institute, Namakkal was utilized for this study.
Preparation and sterilization of semen collection equipment

\section{Glass wares}

Glasswares such as conical flask, beaker and graduated semen collection vialswere soakedin sodium dodecylbenzene sulfonate (Labolene $^{\circledR}$, Fisher Scientific, Mumbai) detergent solution for 20 minutes initially. Then they were washed in tap water followed by rinsing with single distilled water. The glassware were allowed to dry in incubator and covered with aluminium foil. Finally, they were sterilized in hot air oven at $160^{\circ} \mathrm{C}$ for 30 minutes and kept ready for use.

\section{Rubber wares}

The rubber wares such as artificial vagina $(\mathrm{AV})$, inner liner and director cone were soaked in sodium dodecyl benzene sulfonate solution for 20 minutes initially. Then they were washed in tap water followed by rinsing with single distilled water and sterilized in autoclave at 5 psi for 20 minutes and kept ready for use.

\section{Preparation of AV}

The AV used in this experiment was Russian model. The sterilized inner liner was attached inside the rubber cylinder and the edges of the inner liner were folded over the rim of rubber cylinder on either side. The space in between the rubber cylinder and inner liner was filled with hot water of 60 to $70^{\circ} \mathrm{C}$ to maintain the final AV temperature of $40-45^{\circ} \mathrm{C}$. The sterile collection cup was placed on one edge of assembled AV to collect the semen during mounting.

\section{Preparation of bull}

In the previous day of semen collection, the long preputial hairs around the preputial 
orifice of bull no.14 (Nagulan) were clipped to maintain the length of $2 \mathrm{~cm}$. The semen collection was carried out at $6.00 \mathrm{AM}$ before feeding. On the day of semen collection, the prepuce was washed with running tap water followed by normal saline. Then the preputial orifice was wiped with sterile napkin.

\section{Semen collection}

The semen was collected from the bull no. NK 14. Other Kangayam bulls maintained in the semen station were used as dummy during semen collection. The semen was collected twice in a week (Tuesday and Friday) and each time two ejaculates were collected. The bull NK14 was allowed to mount on the dummy. Two false mounts were given before semen collection during every time. On the third mount, the penis was directed in to AV and the semen was collected in the collection Tube. The collected ejaculate was immediately transferred to semen processing laboratory and kept at $34^{\circ} \mathrm{C}$ in the water bath. Totally eight ejaculates were collected for the evaluation and production of frozen semen straws.

\section{Macroscopic evaluation of fresh semen}

Gross motility: Immediately after semen collection, the gross motility of the semen sample was assessed by naked eye based on the swirling movement observed in the collection cup.

Volume: The volume of the ejaculate was measured in milliliter directly from the graduations of the collection tube.

Color: The color of the semen sample was assessed visually by keeping creamy color as standard and further graded based on the intensity of samples. Thick, milky and creamy color ejaculates were taken for further analysis.
Density: A drop of pooled semen sample was placed on clean and grease free glass slide and visually examined for opacity and the semen samples were graded from $D$ to DDDD. Samples which had DDDD and DDD density were used for processing.

Sperm concentration: Concentration of spermatozoa in the semen sample was measured by using Accucell photometer (IMV Technologies, France) (Plate. 4) at 530 nm wave length after diluting $10 \mu \mathrm{l}$ of semen with $3.990 \mathrm{ml}$ of $0.152 \mathrm{M}$ sodium chloride. Semen samples which had above 500 million spermatozoa per $\mathrm{ml}$ and above were taken for further processing.

Presence of foreign material: Immediately after semen collection, the collection tube and semen samples were grossly examined by naked eye for the presence of foreign materials if any.

\section{Results and Discussion}

A total of 24 semen ejaculates, obtained from Kangayam bull No. 14 (Nagulan) by artificial vagina method were evaluated for macroscopic semen attributes such as the ejaculate volume $(\mathrm{ml})$, gross motility (0-5 scale), sperm color, semen density (D to DDDD), sperm concentration (millions/ml) and presence of foreign materials. The mean values of these parameters of neat semen have been depicted in Table 1.

\section{Macroscopic characteristics of fresh semen}

Gross motility: The gross motility of all the ejaculates of Kangayam bull semen ranged from 4 to 5 .

Volume: The volume of Kangayam semen of present study ranged from 3.0 to $4.1 \mathrm{ml}$ with a mean $( \pm$ S.E) of $2.02 \pm 0.16 \mathrm{ml}$. 
Color: The color of present study Kangayam bull semen varied from thick milky yellow to creamy yellow color. Out of 24 samples examined, 20 samples (50 per cent) were in creamy yellow and 4 samples (50 per cent) were in thick milky yellow in color.

Density: The density of Kangayam bull semen varied from DDD to DDDD. Out of 24 samples 21 samples exhibited higher density of DDDD (50 per cent) and 3 samples had medium density of DDD (50 per cent).
Sperm concentration: The concentration of Kangayam bull semen was assessed by using Accucell photometer and the results were presented in Table 1. The concentration of buck semen ranged from 998 to 1210 million per ml with a mean $( \pm$ SE) of $1113.75 \pm$ million per $\mathrm{ml}$.

Presence of foreign materials: Out of 24 semen samples none of the samples had foreign materials.

Table.1 Macroscopic evaluation kangayam neat semen

\begin{tabular}{|c|c|c|c|c|}
\hline Semen characteristics & $\begin{array}{c}\text { No of } \\
\text { samples }\end{array}$ & Grading & Values & Per cent \\
\hline \multicolumn{5}{|c|}{ Macroscopical Evaluation } \\
\hline \multirow[t]{3}{*}{ Volume of semen (ml) } & \multirow[t]{3}{*}{24} & Maximum & 4.10 & - \\
\hline & & Minimum & 3.00 & - \\
\hline & & Mean & $3.65 \pm 0.14$ & - \\
\hline \multirow[t]{2}{*}{ Color } & \multirow[t]{2}{*}{24} & Creamy yellow & $20 / 24$ & 50 \\
\hline & & $\begin{array}{l}\text { Thick Milky } \\
\text { yellow }\end{array}$ & $4 / 24$ & 50 \\
\hline \multirow[t]{2}{*}{ Density } & \multirow[t]{2}{*}{24} & DDD & $3 / 24$ & 50 \\
\hline & & DDDD & $21 / 24$ & 50 \\
\hline \multirow[t]{3}{*}{ Concentration(millions/ml) } & \multirow[t]{3}{*}{24} & Maximum & 1280.00 & - \\
\hline & & Minimum & 998.00 & - \\
\hline & & Mean & $1113.75 \pm 38.35$ & - \\
\hline Foreign materials & 24 & $\begin{array}{c}\text { No of } \\
\text { contaminated } \\
\text { samples }\end{array}$ & Nil & - \\
\hline
\end{tabular}

The volume of semen varies from breed to breed (Ahmed et al., 1993) and influenced by a number of factors such as age, breed, weight and season. Laing (1988) reported that a bull of high fertility produced greater semen volume than that in an in a lower fertility bull. Variation in semen volume has been reported among different species and within a species and even the same male at different time of collection. The volume of semen was reported to vary with breed, age (Rao and Shreemanarayana, 1996), body size, size of accessory sex gland, frequency of collection, exercise, teasing, level of nutrition, effect of season (Saxena and Tripathi, 1981 and Dhamiet al., 1998), and method of collection.

In the present studies the other factors responsible for variation of semen volume are same for all bulls except that level of teasing could have been a factor for variation in semen volume. The mean volume of Kangayam bull semen was $3.65 \pm 0.14 \mathrm{ml}$ observed for the period of three months in 24 
ejaculates. The number of viable bovine spermatozoa deposited in the female reproductive tract influences the fertilizing ability of the cow up to an upper threshold level (Gerard and Humblot, 1991). Sperm concentration in ejaculate is one of the important criteria of semen characteristics to qualify fertile males for breeding purposes (Grafferet al., 1988). Accurate determination of the number of spermatozoa per milliliter of semen is extremely important.

The sperm concentration is highly variable semen characteristics and when combined with ejaculated semen volume it determines number of females that can be inseminated with optimal number of sperm cells (Hafez, 1987). Present study documents the sperm concentration of the Kangayam bull semen in 24 ejaculates is the mean of $1113.75 \pm 38.35$ million/ml. In a study (Kumar, 2011 and Singh, 2012) in Hariana bull semen the sperm concentration (millions $/ \mathrm{ml}$ ) ranges between $938.60 \pm 41.39$ to $2890.0 \pm 118.51$ which was differ compare to the present investigation. The results differ due to effect of age as well as of the season (Das et al., 2007). A slight difference in semen concentration may be due to degree of sexual stimulation. Gross motility of sperms has been an important attribute for acceptance or rejection of the ejaculate for further processing and use in AI and it has been positively correlated with keeping quality, freezability and fertility of that sample (Bhoiteet al., 2008).

The gross motility of neat semen of Kangayam bull varied from 4 to 5 with an overall mean of $4.88 \pm 0.07$ (0-5 scale). The density of the Kangayam bull semen was reported to be DDDD in 21 out of 24 ejaculates in our study. Majority of the ejaculates was light cream and cream colored as reported by Kanchan and J.S. Matharoo, 2015. The present study documented the colour of the Kangayam bull semen especially Sevalai variety was creamy yellow. There should not be any foreign materials in the neat semen which indicates the hygienic semen collection. Thus, the present study reports the macroseminogram of the Kangayam bull semen for the first time.

\section{References}

Ahmed, J. U., Shamsuddin, M., Alam, M. G. S. (1993). Breeding soundness of the bull used for artificial insemination in Bangladesh. Bang. J. Agric. Sci. 20: 225 $-232$.

Ahmad, M., M.T. Asmat, N. U. Rehman and M. Z. Khan. 2003. Semen Characteristics of Sahiwal Bulls in relation to age and season. Pakistan. Vet. J., 23 (4): 202 - 206.

Ajendar Singh Pal, Vijay Singh and Akhil Patel. 2020. Studies on Seminal Attributes of Neat Semen of Hariana Bulls. Int.J.Curr.Microbiol.App.Sci. 9(01): $1742-1749$.

Bailey, J.L., A. Morrie and N. Cormier, 2003. Semen cryopreservation: success and persistent in farm species. Canadian J. Anim. Sci.; 83: 393 - 401

Bhoite, U.Y., Sutar, D.A. and Ulmek, B.R. (2008). Studies on semen quality of crossbred bulls. Indian Vet. J., 85: 395397.

Patel BR and Siddiquee GM (2013) Physical and morphological characteristics of Kankrej bull semen, Vet World 6(7): 405-408.

Bhosrekar M and Nagpaul PK (1972) Studies on effect of exercise on reaction time and semen production. Indian Journal of Veterinary science 25(3): 194-195.

Bramhaiah, K.V., V.H. Rao., A.S. Rao., K.V. Naidu., and S.T. Viroji Rao., 2013.Semen characteristics of Punganur bulls. Indian J. Anim. Res 47: 45-48.

Chikhaliya, P.S., A.R. Ahlawat, G. S. Solanki, R.J. Raval, K.B. Vala and Verma, A.D. 2018. Physical Seminal Attributes of Gir Bull Semen. Int.J.Curr.Microbiol. App.Sci. 7(07): 1152-1159.

Curry, M.R., 2000. Cryopreservation of semen from domestic livestock. Rev. Reprod., 5: $46-52$ 
Das GC, Deori S, Das BK and Goswami RH (2007) Seminal characteristics of the swamp buffalo of Assam. Indian Veterinary Journal 184: 1052-1053

Dhami AJ, Mohan G and Sahani KL (1998) Seasonal influence on quality and freezability of semen of Friesian and Murrah buffalo bulls. Indian Journal Animal reproduction 19(1): 55-58.

Gerard, O., Humblot, P. (1991). Influence of interactions between semen extender and number of spermatozoa on nonreturn estimates of fertility for individual Holstein bulls. Theriogenology. 36: $727-$ 736.CURRY

Graffer T, Solbu H, Filseth O (1988). Semen production in artificial insemination bulls in Norway. Theriogenology.30: 1011- 1021.

Hafez ESE (1987) Semen evaluation: Reproduction in Farm Animal. Sea and Febiger, Philadelphia, PP: 455-480.

Kandasamy N (2001) Kangayam breed of cattle: present status and management practices. In: Indigenous Cattle and Their Role in the New Millennium, Proceedings of the Workshop Organized by TANUVAS, IDA and NDRI on 2425 March at Erode, Tamilnadu, India.

Kanchan and J.S. Matharoo. 2015. Effect of semen colour on seminal characteristics in cattle bulls. Indian J. Anim. Res., 49 (1) 2015: 146-147

Kumar A (2011). Studies on Cryopreservation of Hariana Bull Semen.MVSc Thesis. U.P. Pt. Deen Dayal Upadhyaya Pashu Chikitsa Vigyan Vishwavidyalaya Evam Go Anusandhan Sansthan, Mathura, Uttar Pradesh.

Laing, J. A., Morgan, W. J. B. and Wagner, W. C. (1988). Fertility and infertility in the domestic animal $4^{\text {th }}$ edn. Baillere

\section{How to cite this article:}

Elamurugan Krishnamoorthy, Ezakial Napoleon, Selvaraju Mani, Murali Nagarajan and Palanisamy Mahakrishnan. 2020. Macro Seminogramn Neat Semen of a Kangayam Bull - An Ingenious Study. Int.J.Curr.Microbiol.App.Sci. 9(10): 1809-1814. doi: https://doi.org/10.20546/ijcmas.2020.910.220
Tindall, London

Manivannan, S., M. Selvaraju, R. Ezakial Napolean and Sesh, P.S.L. 2017. PostThaw Evaluation of Cryopreserved Boer Crossbred Buck Semen Extended in TEYG (Universal) Extender and its Fertility Rate. Int.J.Curr.Microbiol. App.Sci. 6(9): 3044-3049.

Prem Kumar, R.P., R. Sunitha, A. Karthikeyan, V. Pradeep Kumar and T.G. Honnappa, 2020. Studies on effect of season on semen characteristics of Hallikar bulls, Journal of Entomology and Zoology Studies; 8(1): 173-176

Rao AVN and Sreemannarayana O (1996) Seminal traits and frozen semen production in relation to age in Murrah bulls. Indian Veterinary Journal 73: 52630.

Rao KB, Naidu GV, Reddy KR, Rao VVVSP. Age at puberty and semen characters in Ongole bulls. Indian J. Anim. Reprod. 2000; 21(2):139-140.

Ritesh Tiwari, G K Mishra, R B Singh, S U Rehman, K S Rathora, S K Saxena and M U Siddiqui. 2012. Seasonal variations in the quality and freezability of Red Sindhi bull semen. Indian Journal of Animal Sciences 82 (11): 1344-1346

Saxena VB and Tripathi SS (1981) Seasonal variations in semen characteristics and preservability in crossbred bulls. Indian Journal of Animal Research 15(1): 1923.

Singh AK (2012). Studies on certain seminal attributes and the effect of dilutors on cryopreservation of Hariana bull semen. MVSc. Thesis. U.P. Pt. Deen Dayal Upadhyaya Pashu Chikitsa Vigyan Vishwavidyalaya Evam Go Anusandhan Sansthan, Mathura, Uttar Pradesh. 